\title{
Countermeasures of the Reform and Innovation of Xi'an Peihua College
}

\author{
Fengxiang Jiang \\ Department of Business, Xi'an Peihua College, Xi'an, Shaanxi Province, China (395745215@qq.com)
}

\begin{abstract}
Xi'an Peihua College's evaluation ended in 2013, which should continue to seize this important opportunity, to concise school characteristics and advantages, to find out problems and deficiencies and improve its conception and construction. To promote the professional construction as the core, and take the talent's training mode reform as the focus, to further strengthen the reform of education and teaching, improve the level of faculty, long-term mechanism to strengthen cooperation, to strengthen the social service ability and level, cultivate dedicated and pragmatic solid-foundation strong-ability practical senior specialized talents for economic development of Shaanxi.
\end{abstract}

Keywords-Peihua University, talents training, teaching reform, research

\section{培华学院改革与创新发展的对策}

\author{
江凤香 \\ 西安培华学院商学院, 西安, 陕西, 中国
}

摘 要 2013 年培华学院评估已经结束, 培华学院应该继续抓住这个重要契机, 凝练办学特色及优势, 查找问题和不足, 完善 自身观念和建设, 以推动专业建设为核心, 以人才培养模式改革为重点, 进一步加强教育教学改革, 提高师资队伍水平, 加强产学研 合作长效机制, 增强社会服务能力和水平, 为陕西经济发展培养敬业务实、基础扎实、实践能力强的高级专门人才。

关键词培华学院, 人才培养, 教学改革, 科研

\section{1. 认清形势, 结合市场和行业需求, 优化学校专业结} 构

学校专业设置应该关注国家发展战略, 结合地方经济发展 特色, 地方产业调整升级与发展方式的改变, 应该结合地 方经济发展对人才的需求信息进行统计分析, 学校应该组 织人员到农村基层、社区基层、行业与政府部门、同类院 校开展调研, 继而优化学校的专业结构和人才培养规格, 具体思路见图 1-1:
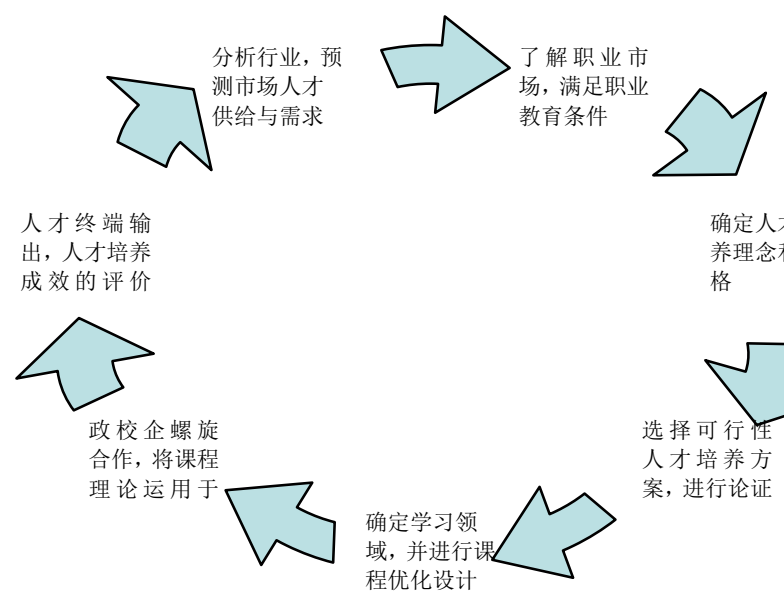

\section{确定人才培} 养理念和规 格

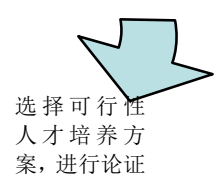

图 1-1：确定人才培养规格的思路

中国教育深受苏联模式的影响, 专业分工很细, 从而出 现的结果就是学生找不到和自己专业对口的工作, 社会就 
更多的原因归结于承担教育职责的学校。结合几年来中国 的就业形势的恶化, 本文认为应该复合专业, 减少知识的 隔离状态。学校应该淘汰不适应专业, 调整优化现有专业, 适度发展新办专业, 形成以商类专业群为主体, 医学和建 工为两翼的框架格局。大学应该强调通识教育, 注重实践 教育, 大学课程设置如图 1-2:

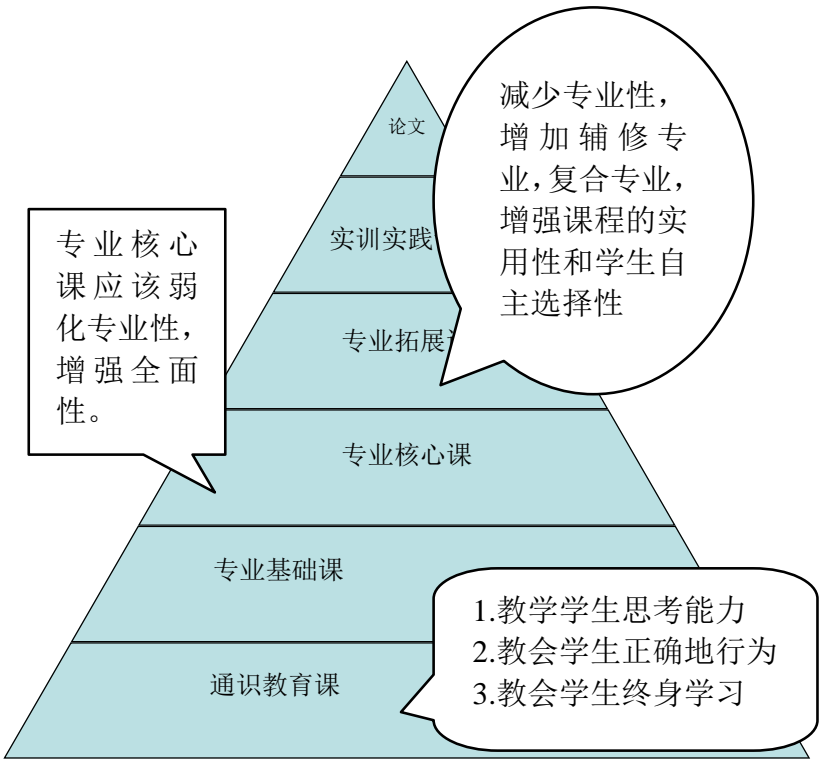

图 1-2: 大学课程设置

\section{2. 完善办学机制, 增强办学能力, 强化学校教学功能}

明确学校的治学目标, 完善管理机制, 中国的公办教 育单位带有很深刻的行政化烙印, 一直热议是否应该去行 政化, 对于民办院校来说, 本身就是市场经济的产物, 更 应该去行政化, 强化教学职能。各级职能部门的设置应该 更好地履行服务部门的职能, 一切行政工作应该是为教学 服务, 教学质量是学校的生命线, 教学质量的高低直接影 响着学生素质的高低, 影响着就业状况。行政尽量不要干 涉教学, 完善学校内部管理机构, 进一步完善法人治理结 构, 实行理事会领导下的院长负责制, 建议进一步放权, 所有权人与经营权人分离。法人治理包括治理结构和治理 机制, 治理结构包括股权结构、资本结构、组织架构; 治 理机制包括用人机制、监督机制和激励机制。法人治理结 构图如图 2-1:

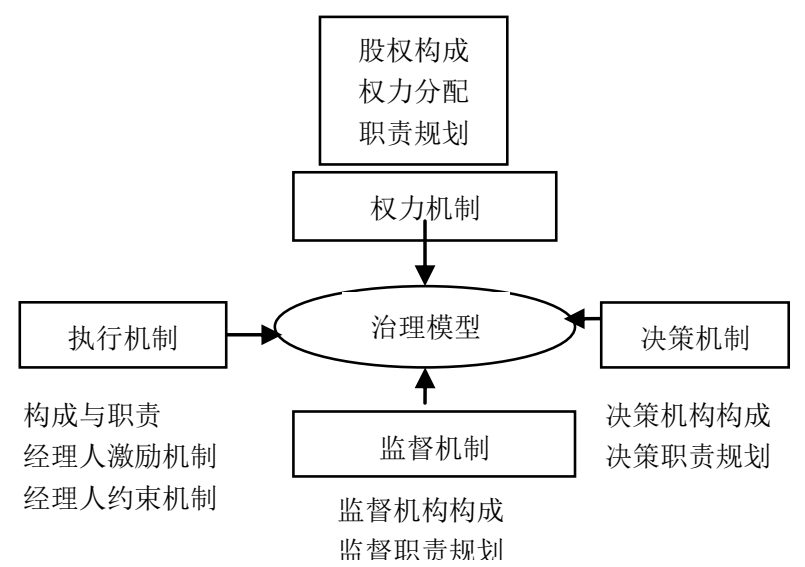

图 2-1：法人治理结构

法人治理有助于提高经济效率。提高劳动者的积极 性, 有利于实现 “人治” 转向 “法治”, 由 “法治” 转向 “文 化治理”, 进一步实现培华学院的组织转型和定格。

\section{3. 教师素质结构重建, 提升科研能力, 注重教学改革}

在培华学院提升教育质量的路上, 到底需要什么样教 师素质结构? 传统认为教师就是传道、授业、解惑, 但是 随着知识经济的到来, 教师应该随着市场经济的变化, 需 要重塑自己的知识结构, 这就需要不断更新理论知识, 结 合社会实践, 创新更多新的理论知识, 从而推动教育质量 的真正提高。教师不仅应具有良好的职业道德、学科知识、 教育教学能力, 还要成为某一领域的专业研究者, 对自己 的工作具有反思态度和积极探索的能力; 教师还应是一个 成功的教育合作者, 善于和学生、同事、领导、社区、家 庭沟通与联系; 教师还应是学校管理的积极参与者。结合 吉登斯的结构化理论, 认为教师应该具备以下素质, 见图 3-1:

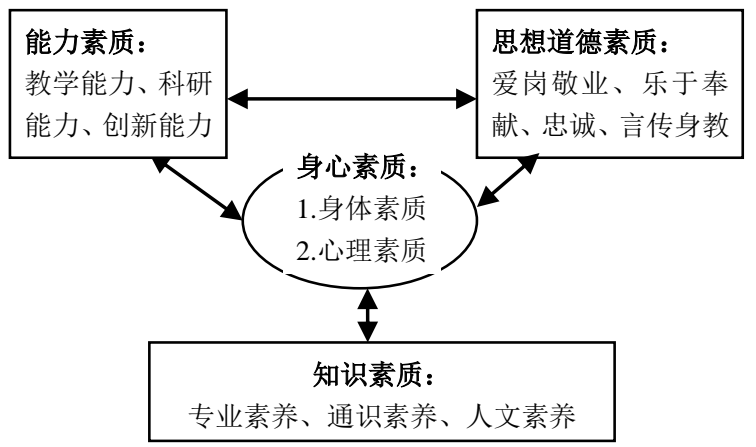

图 3-1: 教师素质要求

教师在教育他人时, 应该树立终身学习的理念, 不断 提高自己的教书技能。随着物联技术的发展、信息时代的 到来、MOOC 等新型接收知识渠道的产生, 教师应该不断 优化自身素质, 通过教学、科研、社会活动, 不断提高自 
身水平。改变传统的以 “有学历就有基础能力+专业能力” “有嘴能说就能当老师” 等等错误观念, 而应该不断反省 自身和自我更新, 坚定 “一定要做一个优秀教师” 的信念。 培华学院也应该为教师职业生涯作以规划, 提供较好的发 展平台, 从物质和精神激励双向出发, 鼓励教师参与教学 改革、鼓励教师参与教学创新、鼓励教师接受再教育、鼓 励教师积极参与科研、鼓励教师热情参与社会实践活动。

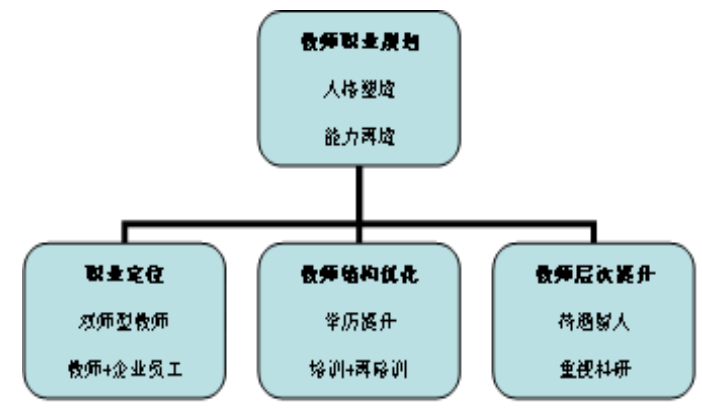

图 3-2: 教师素养提升途径

\section{4. 深化人才培养模式改革, 面向岗位和能力+素养的 人才培养方案}

人才培养模式改革是一个系统工程, 涉及到专业建设、 工程建设、师资队伍建设、教学方法改革等方面。建议各
个二级学院设置创新实验班、卓越人才班级、拔尖人才学 堂、商业人才班。在这些班级或者学堂内部推行进行人才 培养模式、课程体系、教学内容和教学方法改革, 探索全 新的教育理念、培养体系和管理模式。参考中国其他名校 和相类似民办院校人才培养，见表 4-1 和表 4-2。培华学院 各个二级学院, 人才培养应该进行一定的定位, 以 “夯实 基础, 拓宽知识, 强化能力, 提高素质, 发展个性, 激发 潜能” 为原则, 形成 “注重通识教育, 强化学科基础; 形 成方向优势, 发展兴趣特长; 培养职业素养, 增强实践能 力” 的人才培养模式，构建 “宽基础、多方向、重发展、 适应多种岗位需要” 的人才培养模式, 如图 4-1:

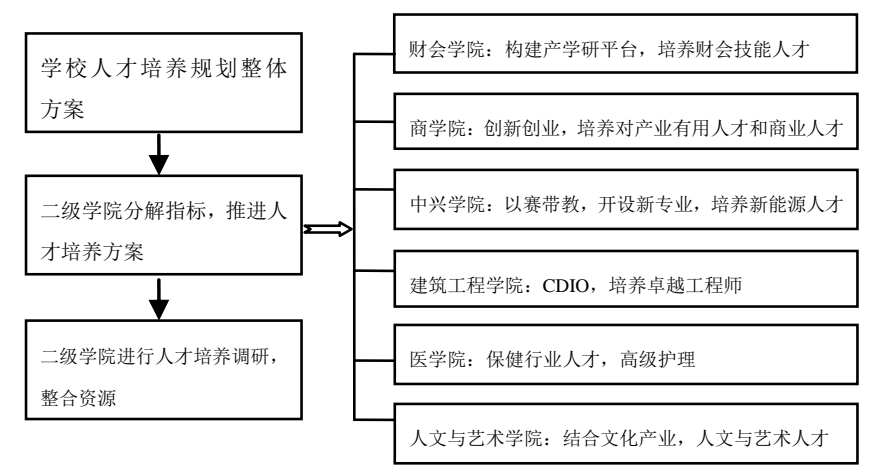

图 4-1：人才培养思路

表 4-1：中国名牌大学人才培养特征

\begin{tabular}{|c|c|}
\hline 学校 & 人才培养特征 \\
\hline 清华大学 & $\begin{array}{l}\text { 清华学堂人才培养计划。成立数学班、物理班、化学班、生命科学班、计算机科学实验班、钱学森力学班。聘请知名 } \\
\text { 学者甚至大师担任首席教授, 由他们主持制定培养方案, 组织协调项目实施。 }\end{array}$ \\
\hline $\begin{array}{l}\text { 人民大学 } \\
\text { (中国) }\end{array}$ & $\begin{array}{l}\text { 本科人才培养路线图的研究型学习制度包括八大制度, 精实课程制度、国际研学制度、名师沙龙制度、拓展支持制度、 } \\
\text { 全员导师制度、研究实践制度、双选认证制度和公益服务制度, 引入项目实施人才培养方案。 }\end{array}$ \\
\hline 北京大学 & $\begin{array}{l}\text { 北大以 “加强基础、淡化专业、因材施教、分流培养” 为方针的教学改革, 促进学科调整和整合, 使学生入学后能够 } \\
\text { 得到宽口径、厚基础的培养, 避免学生因过早进入专业学习而知识面狭窄的弊端。学生在低年级学习基础课程, 高年 } \\
\text { 级时进入学科领域, 学习专业课程。学生通过对学科、专业的学习和了解后, 结合兴趣、特长, 再在院系范围内自主 } \\
\text { 选择专业, 通过学习进行选择, 通过选择完成学习。为了实现本科阶段低年级通识教育和高年级宽口径专业教育相结 } \\
\text { 合的教育理念, 推行本科生的 “导师制”, 为学生提供全方位的服务。 }\end{array}$ \\
\hline 复旦大学 & $\begin{array}{l}\text { 复旦大学的本科教学原则是“通才教育, 按类培养”, 教学理念是“厚基础、宽口径、重能力、求创新”, 注重加强学科 } \\
\text { 间的渗透、交叉、组合, 将“普通教育, 基础教学, 专业教学”三个方面的教学内容有机地结合起来。复旦大学新闻学 } \\
\text { 院本科生 “ } 2+2 \text { ” 培养模式, 本科前两年夯实基础, 在不同学科中汲取思想养料, 增长更多知识, 从本科三年级开始, } \\
\text { 再根据所选择的专业方向集中学习理论课和实践课。 }\end{array}$ \\
\hline 浙江大学 & $\begin{array}{l}\text { 坚持 “以人为本、整合培养、求实创新、追求卓越”, 人才培养模式是以 } 3 \mathrm{M} \text { (多规格、多通道、模块化) 和“宽、专、 } \\
\text { 交”为特征的 } \mathrm{KAQ} \text { (知识、能力、素质) 并重, 把 } 112 \text { 个本科专业分成若干学科大类, 实行前期按大类培养, 实施通 } \\
\text { 识教育, 后期实行宽口径专业教育的新模式, 并着力构建大学本科教育课程体系。 }\end{array}$ \\
\hline $\begin{array}{l}\text { 北京师范大 } \\
\text { 学 }\end{array}$ & $\begin{array}{l}\text { 励耘基础学科拔尖学生培养试验计划, 旨在改革培养模式, 创新管理模式, 实施导师指导下的开放式“宽口径、厚基 } \\
\text { 础、高素质、强能力、个性化、本-研衔接”拔尖学生培养模式。积极探索拔尖创新人才培养规律, 努力把学生培养成 } \\
\text { 为兴趣浓厚、志向远大、基础扎实、能力突出、德才兼备、勇于创新的拔尖学生, 为他们成为相关基础学科的领军人 } \\
\text { 物、知名学者奠定坚实的基础。同时, 通过计划实施的示范和辐射作用, 带动全校人才培养质量的全面提升。 }\end{array}$ \\
\hline $\begin{array}{l}\text { 北京航天航 } \\
\text { 空大学 }\end{array}$ & $\begin{array}{l}\text { 1. 大类招生+通识教育+自选专业+本科导师制+完全学分制 } \\
\text { 2. 未来人才培养方向: 争取到 } 2016 \text { 年实现全校打破院系壁垒, 实现按照文、理、工、管理等学科大类招生培养 }\end{array}$ \\
\hline
\end{tabular}


表 4-2: 中国民办大学人才培养特征

\begin{tabular}{|c|c|}
\hline 学校 & 人才培养特征 \\
\hline 北京吉利大学 & $\begin{array}{l}\text { 多元人才培养模式让校企实现深度合作。吉利大学提出培养国际化创新型应用型人才, 和市场化、职业化接轨, } \\
\text { 同企业对接。学院从对学生未来的就业、职业规划的角度出发, 设立双导师、双评估、双课堂、双教学的 “四双 } \\
\text { 模式, “311 就业导向教育模式” 简单地说就是以培养学生表达交流、就业上岗、团队合作、批判思维和终 } \\
\text { 生学习等五种能力为目标, 以就业导向与职业需要制定专业标准和课程体系, 以理论与实践一体化的项目训练为 } \\
\text { 主要教学形式, 以启发式、引导式、互动式为主要教学方法, 以产学联合培养为依托, 培养解决问题、能力强、 } \\
\text { 专业应用水平高、职业素质好的应用型、技能型、创新型人才的教育模式。 }\end{array}$ \\
\hline $\begin{array}{l}\text { 湖南涉外经济 } \\
\text { 学院 }\end{array}$ & $\begin{array}{l}\text { 为了充分挖掘应用型人才培养的内涵, 同时提高教学质量, 湖南涉外经济学院根据不同性质的课程教学要求, 积 } \\
\text { 极推广计算机辅助教学、多媒体教学技术、虚拟技术等现代信息技术, 实现教学方式、学习方式的变革, 扩大课 } \\
\text { 堂教学的信息量, 注重提高课堂教学效果, 发挥网络资源共享的优势, 发挥学生的主体地位, 指导学生利用网络 } \\
\text { 环境进行自主探究、发现学习。湖南涉外经济学院号召并动员学生投身科学实践, 积极开展学术研究、科技文化 } \\
\text { 活动, 主动营造学校浓厚的学术氛围, 丰富校园的文化生活, 提升自身的学术素养湖南涉外特别设立了 “大学生 } \\
\text { 创新基金”课题: 鼓励学生参加大学生研究性学习与创新型实验计划项目, 激发学生参与科研工作的热情。“外语 } \\
+ \text { +专业+技能+创业素质”培养模式共享国际教育学习资源。 }\end{array}$ \\
\hline 西安欧亚学院 & $\begin{array}{l}\text { 在具体的模式搭建上, 该院研发出了具有自身特色的人才培养模式图。主要是学校依据企业人才需求订单, 与企 } \\
\text { 业共同制定培养方案、共同开发课程、共同管理学生、共同管理教学过程、共同塑造人文理念、共同促进学生就 } \\
\text { 业, 最终实现学生从高中毕业生到高技能应用型人才的转变。师资来源主要为订单需求的校内外专兼职教师, 外 } \\
\text { 聘校外专 (行) 业教师或专家, 企业培训讲师, 企业中、高层管理人员等。其中校内外专兼职教师主要负责单项 } \\
\text { 课程的教学任务, 外聘行业教师组成师资队伍的核心部分参与专业建设、课程设计, 由学校骨干教师和企业讲师 } \\
\text { 组成的“校企双师型教学团队”担负课程改革的主体部分 (企业人员占比 } 85 \% \text {, 负责研发课程, 针对性地进行订 } \\
\text { 单教育的课程开发, 避免订单课程建设与开发滞后。通过校企深度合作, 双方共同来培养人才。 }\end{array}$ \\
\hline 西京学院 & $\begin{array}{l}\text { 建立高等教育研究所, 研究民办高等教育规律及应用型人才培养模式; 积极搭建 “产学研” 合作平台, 对内开展 } \\
\text { 科技项目瞬化, 对外开展校企合作和技术开发服务。以工科为主, 发展特色专业。 }\end{array}$ \\
\hline
\end{tabular}

\section{5. 建立产学研协同机制, 促进实践教学改革, 培养实 践与创新能力人才}

产学研合作培养人才模式是以培养学生优良素质、综 合能力和就业能力为重点, 充分利用学校、企业、科研机 构等多种不同教育环境和教育资源以及人才培养方面的各 自优势, 形成 “教与学、理论与实践、学校与企业紧密结 合” 的人才培养模式。现在人才培养就业能力的欠缺, 促 使高校思考如何加强学生实践技能的提高。建议学校以项 目带动学与科研, 鼓励教师与学生的参与, 而达到人才培 养目标, 如图 5-1:

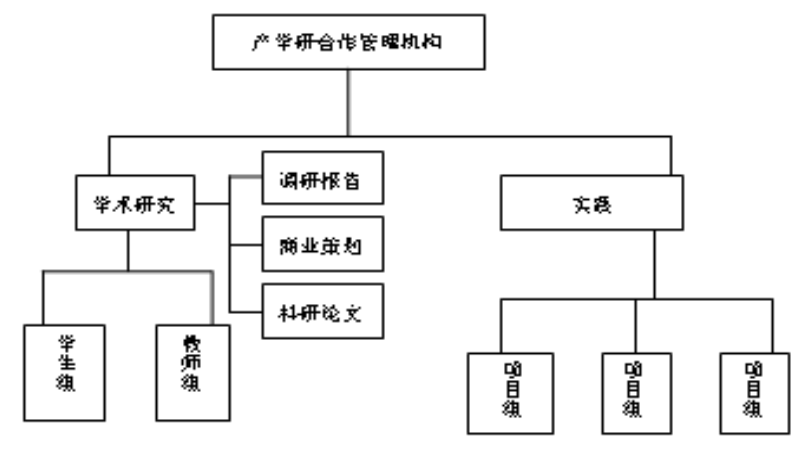

图 5-1：产学研合作机制
总之, 全面提升教育质量, 培养社会满意人才, 创新 创业教育是发展趋势, 产学研结合是必要手段, 教学改革、 教学方法创新、重视师资队伍建设, 形成具有专业特色的 人才培养方案, 搭建校内和校外的教学平台, 推动学院改 革和创新, 培养实践能力强、高素质的创新性、应用型人 才。

\section{参考文献 (References)}

[1] Nianliang $\mathrm{Li}$, and Baoxing $\mathrm{xu}$, "Personnel Training Model Reform and Practice Research of the Private Colleges Based on the Collaborative Innovation -- Taking Guangdong Baiyun University as an example ,'Guangdong Education: Vocational Education Edition, pp. 30-33, September,2013.

[2] Hu Jintao's convention speech in Tsinghua University celebrating the 100 anniversary of the People's Daily, April 2011.

[3] Wu Daguang. Strengthen the ability of scientific research to promote collaborative innovation. China Education daily, May2011.

[4] Wang Zhen. Construction Teachers team of cultivation of innovative talents. Science and Technology Information. pp. 17-17, 2009. 